\title{
Comparison in practical applications of crown ether sensor molecules containing an acridone or an acridine unit - a study on protonation and complex formation
}

\author{
Ádám Golcs ${ }^{1}$ [D $\cdot$ Panna Vezse $^{1} \cdot$ Bálint Árpád Ádám ${ }^{1} \cdot$ Péter Huszthy $^{1} \cdot$ Tünde Tóth $^{1,2}$
}

Received: 6 April 2021 / Accepted: 29 May 2021 / Published online: 8 June 2021

(c) The Author(s) 2021

\begin{abstract}
Crown ethers containing an acridone or an acridine unit are successfully applied opto- and electrochemical cation sensors. The heteroaromatic unit of these macrocycles can be in different forms during the applications, which have a strong influence on the sensing behavior. Moreover, in the case of acridono-macrocycles a prototropic equilibrium takes place upon complexation, which is effected by the physicochemical characteristics. $\mathrm{A} \mathrm{Pb}^{2+}$-selective acridono-18-crown- 6 ether and its 9-phenylacridino-analogue were used as model compounds for comparing the different forms of the heterocyclic units of these sensor molecules. Since in most practical sensor applications of the fluorescent hosts a non-neutral aqueous medium is present, studies on complexation and signaling were carried out from the aspect of the relationship among protonation, coordinating ability, complex stability and tautomeric equilibrium. A strong interdependence among these factors was found and limitations of using unsubstituted acridino- and acridono-sensor molecules in comparison with their 9-substituted-acridinoanalogues were discussed. This study will hopefully serve as a useful standpoint for future development of ionophore-based sensors containing an acridone or an acridine unit.
\end{abstract}

Keywords Molecular recognition · UV/Vis spectroscopy $\cdot$ Spectrofluorimetry $\cdot$ Tautomerism $\cdot$ Complex stability · Protonation

\section{Introduction}

Acridines and acridones are widely used compounds in analytical and medicinal chemistry [1]. These heterocycles also show a great importance in the field of molecular recognition as they are often used as units of several host molecules, due to the effective coordinating ability of their nucleophilic nitrogen atom toward various cations and their advantageous properties like structural rigidity, strong fluorescence, photostability, etc. [1]. The first acridino- and acridono-crown ethers were synthesized in the late $1990 \mathrm{~s}$ [2]. Since then, several sensor molecules containing an acridone

Ádám Golcs

golcs.adam@edu.bme.hu

1 Department of Organic Chemistry and Technology, Budapest University of Technology and Economics, Szent Gellért tér 4, H-1111 Budapest, Hungary

2 Institute for Energy Security and Environmental Safety, Centre for Energy Research, Konkoly- Thege Miklós út 29-33, H-1121 Budapest, Hungary or an acridine unit have been synthesized for various applications [3-14]. As we are interested in the synthesis and application of new acridino- and acridono-host molecules, a study on the application influencing properties and their molecule structural background plays an important role in the effective future development.

Acridine is a weakly basic $\left(\mathrm{p} K_{\mathrm{a}}\right.$ (conjugate acid) $=5.4$ in water) [15] heterocycle. Oxidation of acridine gives stable acridin-9(10H)-one, shortly called acridone, which contains a carbonyl group at position 9 of the heterocycle. Previous studies showed that in the case of acridono-macrocycles tautomerism takes place upon the complexation with cationic species $[16,17]$. The host molecule suitable for coordination is in its hydroxyacridine tautomeric form in the complex $[16,17]$. Reduction of acridine gives acridane, which is an unstable compound, thus its derivatives are generally not suitable for practical applications. Regarding structural features, hosts containing an acridine unit are considered to be the most advantageous ones for recognition of cations, because of the nucleophilicity of the nitrogen and the ability of the electron rich tricyclic system for $\pi$-interactions. 
On the other hand, acridines containing a hydrogen atom at position 9 have a high tendency to oxidation, thus their conversion to the stable acridones takes place during the applications. Oxidation of the acridine unit can be avoided by the substitution of the hydrogen atom at position 9 resulting in a stable derivative.

Regarding various applications, the focus of the development of crown ether type sensor molecules can be traditionally divided in two large categories: optochemical- and electrochemical ones. Although in the case of electrochemical sensors the signaling is not directly determined by the molecular form of the heteroaromatic unit, in the case of optical signaling the outstanding quantum yield of the acridone form results in an increased signal strength in most cases. In practice, the ionophores are usually immobilized physically or covalently into synthetic membranes, which provides the regenerability and the stable operation of the obtained analytical devices. The high lipophilicity of acridino-crown ethers $(\log P \sim 8$ predicted by the $\log D$ Calculator Plugin of ChemAxon for the parent acridino-18-crown-6 ether) gives an opportunity for physical immobilization in apolar membranes. Moreover, the macrocycle can be tailored to further enhance the lipophilic character or to arm with reactive groups for covalent embedding. Since these modifications of the oligoether unit usually have a weak effect on molecular recognition of achiral guests, parent crown ethers are suitable model compounds for general studies on the effects governing applications.

Molecular recognition-based sensor applications are influenced by several factors, like the counterion of the ionic guest, the solvent, the polarity of the medium, the temperature, etc. Thus, it is difficult to reveal general structure-activity relationships, even in a relatively small group of sensor molecules as crown ethers containing an acridone or an acridine unit. However, studies can be simplified by neglecting certain conditions for example polarity-dependent factors, since in most of the practical applications the ionophores are embedded in apolar membranes and the analyte is in an aqueous solution. Similarly, the measurements are usually carried out at room temperature. The main factor that is always present due to the generally examined aqueous samples is the $\mathrm{pH}$ of the medium, in which the measurements are carried out. Protonation of the nitrogen of the sensor molecules and their prototropic conversion, if it takes place, have strong effects both on complexation and signaling. As it was previously mentioned, the electrochemical signaling is not directly effected by the molecular form of the heterocyclic unit in the hosts, the spectrophotometric methods provide more information about the signaling properties of these sensor molecules. Therefore, the molecular recognition abilities of crown ethers containing an acridone or an acridine unit were optochemically investigated from the aspect of the relationship between complex formation and protonation, since they can be considered as the most important characteristics effecting the practical application of the fluorescent hosts as sensor molecules.

The key structural transformations and equilibrium processes during the applications of sensor molecules containing an acridone or an acridine unit are summarized in Scheme 1.

The present studies were carried out using the examples of a $\mathrm{Pb}^{2+}$-selective 9-phenylacridino-18-crown-6 model compound (as an example for compound $\mathbf{3}$ see Scheme 1) and its $\mathrm{Pb}^{2+}$-selective acridono-analogue 4 (detailed information regarding the molecular recognition abilities of the applied sensor molecules is reported previously [18, 19]). This comparison study can provide generalizable relationships for the effective future development of ionophorebased cation sensors containing an acridone or an acridine unit.

\section{Results and discussion}

\section{Spectrophotometric studies on acridono-crown ether type macrocycles}

Initially, acid titration of acridono-crown ether $\mathbf{4}$ as a $\mathrm{Pb}^{2+}$-selective sensor molecule was performed by UV/Visand fluorescence spectroscopies for studying acridono-macrocycles in acidic conditions (Fig. 1). Crown compound 4 was dissolved in acetonitrile, as it is practically insoluble in water. Solutions of concentrated nitric acid in acetonitrile were added in 0-40 molar equivalents to crown ether 4 .

It can be seen that the absorbance decreased upon addition of the acid at the wavelength of the absorption maximum $(251 \mathrm{~nm}$ ), while at $265 \mathrm{~nm}$ (wavelength at the maximum of the other characteristic absorption band) an increase in absorbance was observed (see part $a$ and $b$ in Fig. 1). The nitrogen atom of the acridone unit does not show a basic character. (The $\mathrm{p} K_{\mathrm{a}}$ values of some macrocyclic analogues of crown ether 4 were previously determined [20].) Thus, the observed spectral changes in acidic conditions were probably caused by solvatochromic effects. This assumption is consistent with the fact that the photophysical properties of acridine derivatives are generally extremely sensitive even to small polarity changes of the medium [21]. In the case of fluorescence titration, a slight decrease in the intensity of emission was observed, which can also be attributed to solvatochromic effects (see part c and d in Fig. 1). However, partial protonation of host $\mathbf{4}$ cannot be totally excluded based on the results.

The addition of 200 molar equivalents $\mathrm{Pb}^{2+}$-perchlorate (the end point of $\mathrm{Pb}^{2+}$-titration based on previous studies on the same crown ether [18]) to the solution of crown ether 4 
Scheme 1 The typical structural transformations during the practical applications of crown ether type host molecules containing an acridone or an acridine unit (The studied processes and model compounds were indicated in red and the curved arrows represent the equilibrium shifting effects)

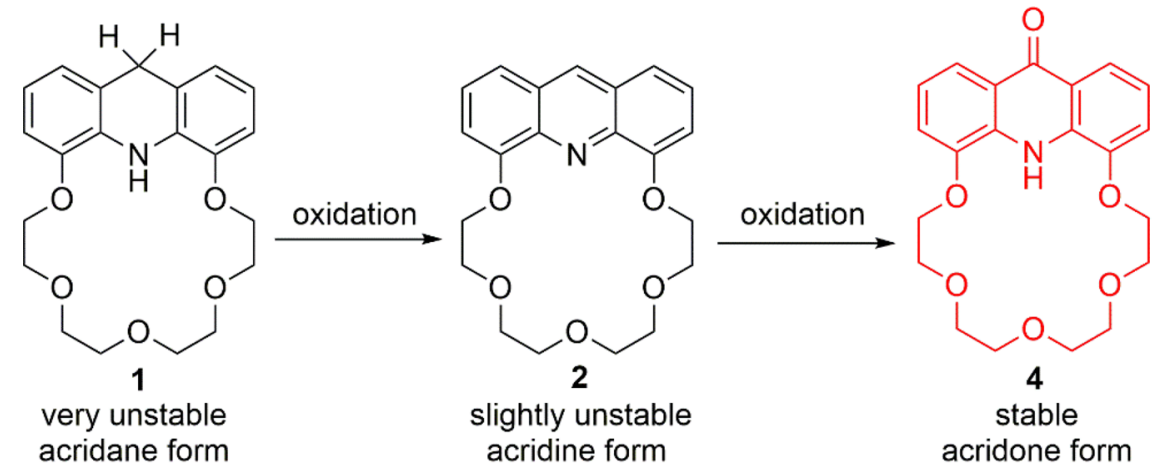

(1)

3

$\mathrm{X}=$ various substituent without $\alpha-\mathrm{H}$ ( $\mathrm{X}=\mathrm{Ph}$ in this study) stable acridine form

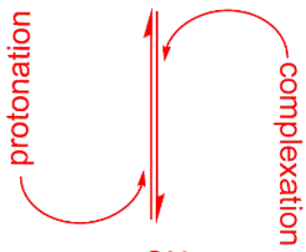

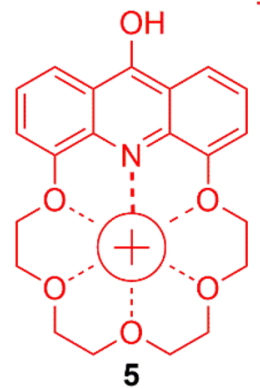

$\oplus=$ cationic guest species

stable hydroxyacridine form resulted in a significant spectral change upon complex formation (Fig. 2).

The spectral change indicated that the electronic structure of the host molecule was also altered and the acridone unit transformed to its 9-hydroxyacridine tautomeric form due to complexation (see part b in Fig. 2).

Therefore, when the $\mathrm{Pb}^{2+}$-complex of crown ether 4 was titrated with an acid, different spectral changes were observed compared to those of the free host molecule with a heteroaromatic unit in its acridone form (in the case when the tendency to form a complex is stronger than that is for protonation). The 9-hydroxyacridine tautomeric form of complexed host molecule $\mathbf{4}$ contains an acridine-like nitrogen atom, which shows a weakly basic character [15]. In order to compare the spectra of the acid titration of the free host and the complex, the $\mathrm{Pb}^{2+}$-complex of crown ether 4 was also titrated with nitric acid in the same way as previously described (Fig. 3).

In the case when acid was added to the complex an increase in absorbance was observed up to the addition of 0.8 molar equivalents of it (see part a of Fig. 3 ). In contrast, additions of 0.8 to 40 equivalents of acid caused quenching in absorbance (see part b of Fig. 3). It suggests that the tautomeric equilibrium of the heteroaromatic unit shifts toward the acridone form due to the protonation of the 9-hydroxyacridine tautomer. At the end point of the titration (after addition of $40 \mathrm{eq}$ acid) the spectrum returned to that of a similar one of free acridono-macrocycle 4 (see part c of Fig. 3).

The same titration procedure was also carried out using fluorescence spectroscopy (Fig. 4).

The results of the two measurements were consistent. Trends in the series of spectra changed direction after the addition of 0.8 molar equivalents of acid.

\section{Spectrophotometric studies on acridino-crown ether type macrocycles}

Studies were carried out in the same manner using the example of $\mathrm{Pb}^{2+}$-selective 9-phenylacridino-crown ether derivative $\mathbf{3}$ as a model compound for acridino-type crown ethers. 
A
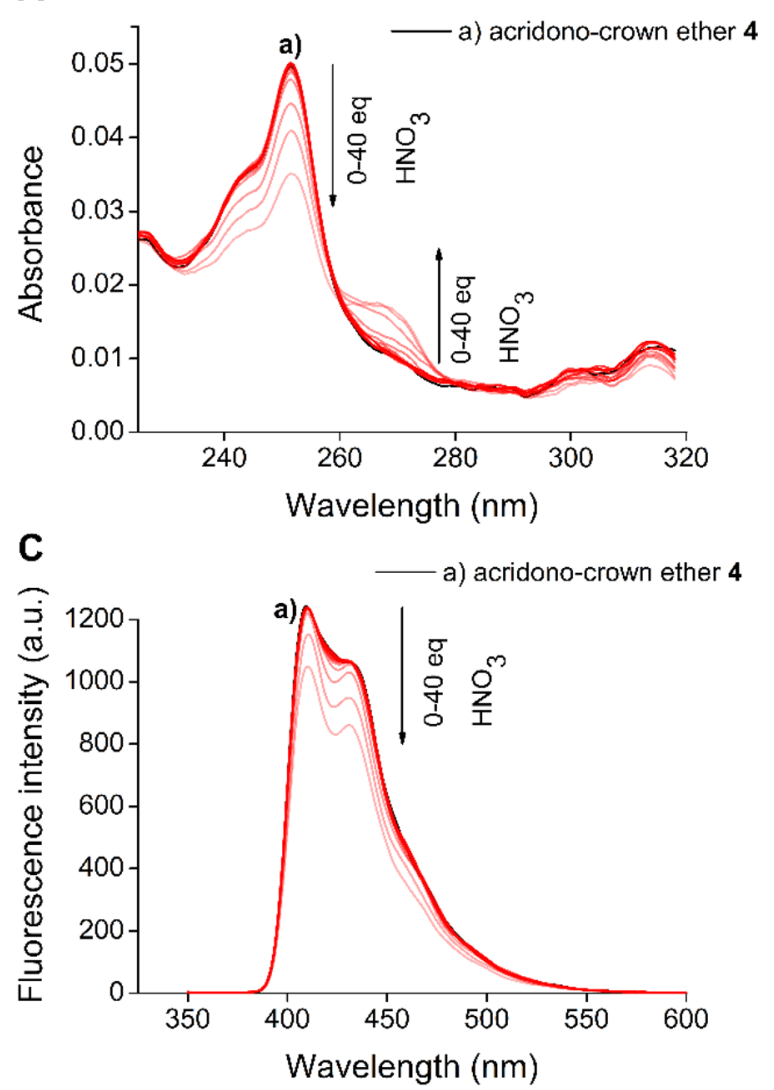

Fig. 1 Series of spectra for UV/Vis- and fluorescence titrations of acridono-crown ether 4 with nitric acid solutions $(0,0.01,0.05,0.1$, $0.2,0.4,0.6,0.8,1,2,3,4,10,20,40$ eq) (a: Changes in absorbance in the presence of acid, $\mathbf{b}$ : Titration spectra at two different character-
B
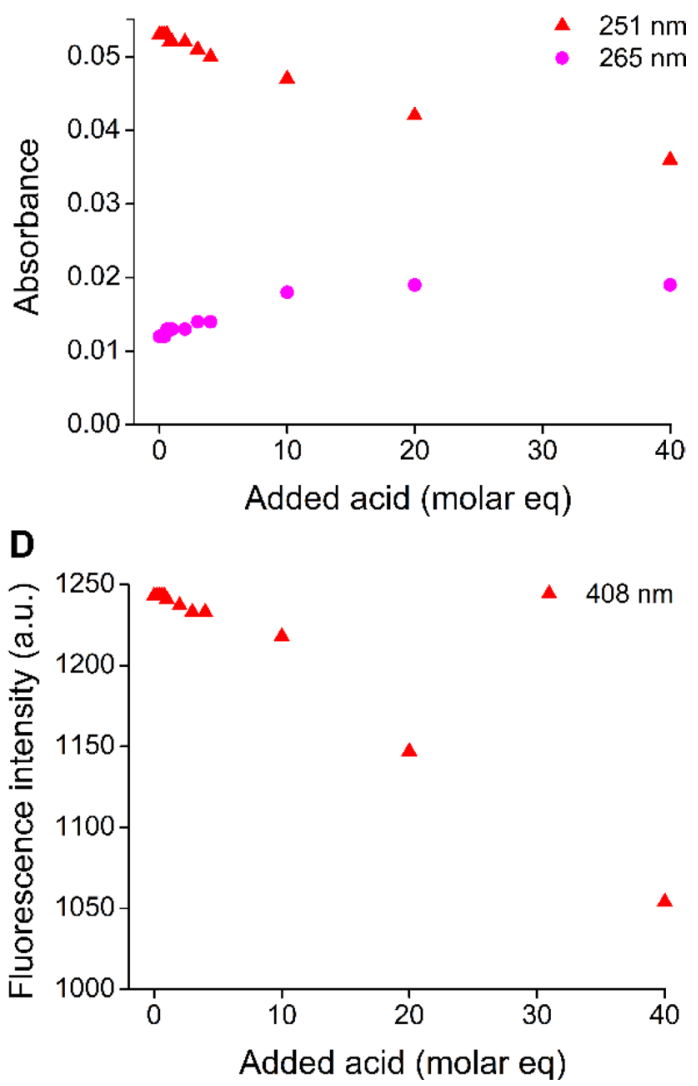

istic absorption wavelengths of the macrocycle, $\mathbf{c}$ : Changes of fluorescence in the presence of acid, $\mathbf{d}$ : Titration spectrum at the emission peak wavelength of the macrocycle)

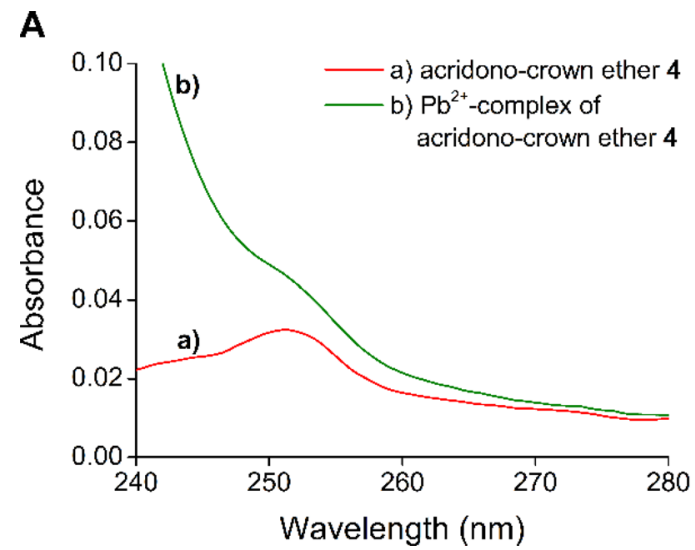

B

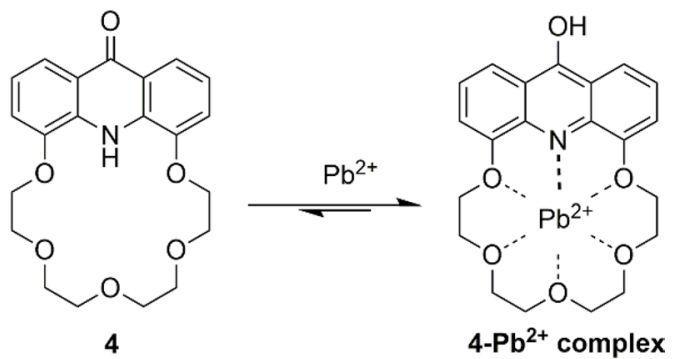

Fig. 2 Absorption spectra of free acridono-host molecule 4 and its $\mathrm{Pb}^{2+}$-complex $\left(\mathbf{a}, \mathrm{c}_{\text {crown ether }}=0.5 \mu \mathrm{mol} / \mathrm{L}\right)$ and the tautomeric transformation of the heteroaromatic unit of macrocycle $\mathbf{4}$ upon complexation (b)

The spectra obtained from the titration of the free macrocycle with nitric acid are shown in Fig. 5.

Protonation resulted in an isosbestic point in the absorption spectrum (see parts a and b of Fig. 5), while it causes an almost total quenching in fluorescence (see parts $\mathrm{c}$ and $\mathrm{d}$ in Fig. 5). In addition to it, a bathochromic shift was also observed (446 nm $\rightarrow 486 \mathrm{~nm}$ ). The spectral change as a function of the amount of the added acid was significantly 
A

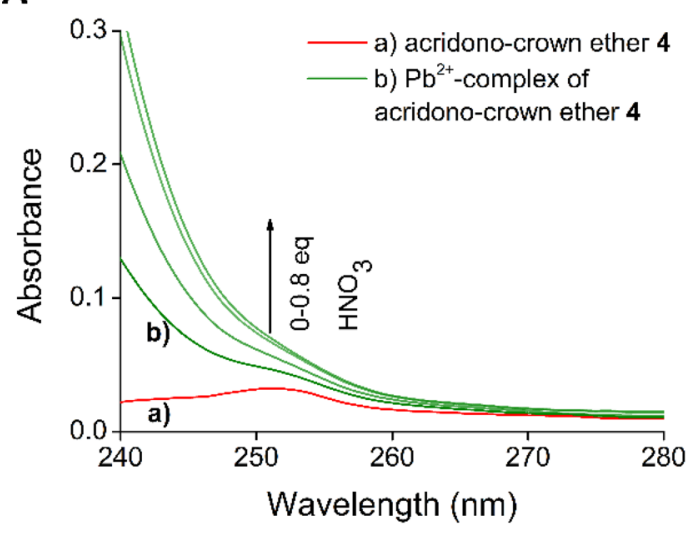

C



\section{(1)}

B

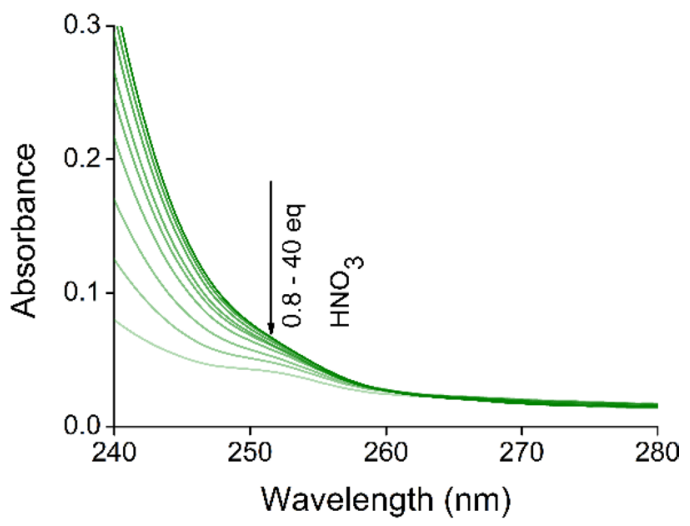

Wavelength $(\mathrm{nm})$
Fig. 3 Series of spectra for UV/Vis-titration of the $\mathrm{Pb}^{2+}$-complex of acridono-crown ether $\mathbf{4}$ with nitric acid (a: Changes in absorbance in the presence of $0-0.8$ eq acid, $\mathbf{b}$ : Changes in absorbance in the pres- ence of $0.8-40$ eq acid, C: Changes in absorbance by adding nitric acid to the complex at its absorption maximum) greater in the case of acridino-macrocycle $\mathbf{3}$ than that for acridono-crown ether 4 . It suggests that the crown ether stabilized by substitution at position 9 in its acridine form is more sensitive to acidic medium due to its increased basicity compared to the acridone form.

Subsequently, 200 molar equivalents of $\mathrm{Pb}^{2+}$ were added to the solution of acridino-macrocycle 3 . The resulted spectrum is shown in Fig. 6.

The observed significant spectral change indicated complex formation.

After addition of 200 molar equivalents of $\mathrm{Pb}^{2+}$ the resulting complex was titrated with nitric acid (Fig. 7).

In contrast to acridono-macrocycle $\mathbf{4}$, the absorbance decreased gradually, thus presumably the protonation of a single molecular form took place (see part $a$ and $b$ in Fig. 7). In the case of fluorescence measurements the results (see part $\mathrm{c}$ and $\mathrm{d}$ in Fig. 7) were close to those obtained during the protonation of free acridino-host molecule 3 (see part c and d in Fig. 5). It also suggests that the protonation of the acridino-crown ethers is less effected by the complexation than that of the acridono-analogues.

\section{Changes in the $\mathrm{p} K_{\mathrm{a}}$ of protonated macrocycles upon complex formation}

As it was mentioned earlier, the nitrogen atom of acridono-crown ethers is not basic. In the case of these macrocycles, complexation induces tautomerism of the heterocyclic unit, which has been previously confirmed by IR- and ${ }^{1} \mathrm{H}$-NMR spectroscopies and single-crystal X-ray diffraction [16, 17]. These studies - in accordance with the present work - support that the 9-hydroxyacridine tautomeric form is preferred during the complex formation. Theoretically, the $\mathrm{p} K_{\mathrm{a}}$ of the protonated acridono-crown ether complex could be determined by the protonation of the basic nitrogen of its 9-hydroxyacridine tautomeric form (5). However, based on this study it is assumed that the heteroaromatic unit is converted back to its tautomeric acridone form upon protonation, which inhibits complex formation. Hence, the $\mathrm{p} K_{\mathrm{a}}$ for this complex equilibrium system cannot be determined spectroscopically due to the copresence of the acridone tautomeric form. 

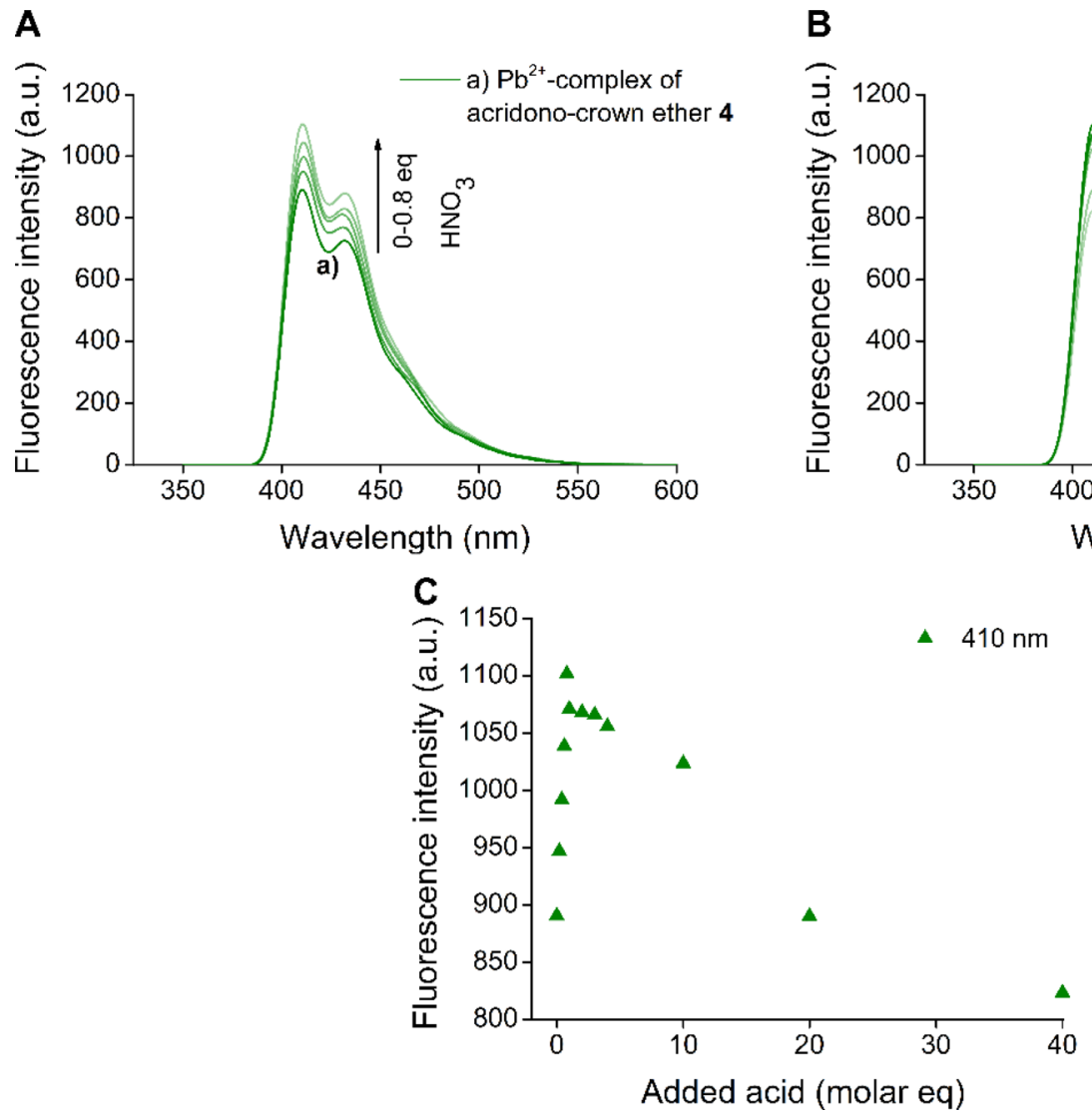

Fig. 4 Series of spectra for fluorescence titration of the $\mathrm{Pb}^{2+}$-complex of acridono-crown ether $\mathbf{4}$ with nitric acid (a: Changes in fluorescence in the presence of $0-0.8$ eq acid, $\mathbf{b}$ : Changes in fluorescence in

Determination of the $\mathrm{p} K_{\mathrm{a}}$ values for protonated acridinocrown ether 3 and its $\mathrm{Pb}^{2+}$-complex (regarding the deprotonation process of the protonated nitrogen of the acridine moiety of the macrocycle) was performed based on the calculation described in Experimental section. A global nonlinear regression method was carried out and the $\mathrm{p} K_{\mathrm{a}}$ values were determined based on a mathematical function fitted according to the least square's method over the entire wavelength range of the titration spectra. The fitted curves for crown ether 3 and its complex are shown in Fig. 8.

The $\mathrm{p} K_{\mathrm{a}}$ values of protonated acridino-crown ether 3 and its $\mathrm{Pb}^{2+}$-complex were found as $8.86 \pm 0.19$ and $7.96 \pm 0.22$, respectively. It can be seen that the $\mathrm{p} K_{\mathrm{a}}$ of the protonated macrocycle decreased by approximately one unit as a result of complex formation. In the case when the lone pair of the nitrogen atom of the host molecule is involved in the coordination with the guest molecule, the basicity of the heteroatom decreases. The change in the $\mathrm{p} K_{\mathrm{a}}$ value also shows that protonation and complex formation are in a competitive relationship with each other.

Based on our previous experience, the $\mathrm{pH}$-independent working range of the membrane-embedded

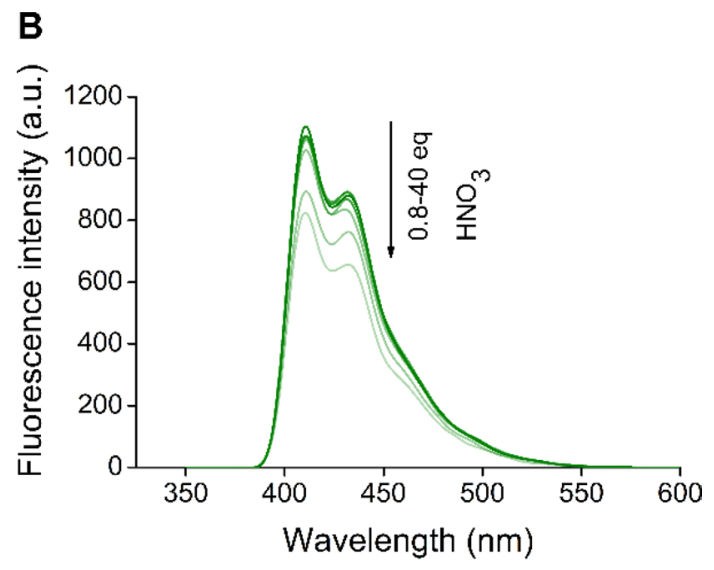

- $410 \mathrm{~nm}$

the presence of $0.8-40$ eq acid, $\mathbf{C}$ : Changes in fluorescence intensity by adding nitric acid to the complex at its emission maximum)

acridono-macrocycles applied as both optical and electrochemical $\mathrm{Pb}^{2+}$-sensors ranged from the neutral $\mathrm{pH}$ to $4.0-4.3$ [22, 23]. In more acidic conditions, protonation of the nitrogen of the crown ethers caused deviance in the response of the sensors. Detection was carried out in aqueous medium in all cases, in which the conjugate acid of the parent acridine has a $\mathrm{p} K_{\mathrm{a}}$ of 5.4 [15]. In the presence of $\mathrm{Pb}^{2+}$, the acridono-crown ether is expected to behave (according to the $\mathrm{p} K_{\mathrm{a}}$ ) similarly to the protonated acridine when the $\mathrm{pH}$ of the medium changes. From this assumption it can be stated that the $\mathrm{p} K_{\mathrm{a}}$ values of acridono-macrocycles in their hydroxyacridine forms do not change in the presence of $\mathrm{Pb}^{2+}$. Thus, for acridono-crown ethers, complexation would not inhibit protonation and vice versa. However, it is only a presumption. When acridono-crown ethers were used as optochemical $\mathrm{Pb}^{2+}$-sensors, we have previously hypothesized that there should be a competition between complex formation and protonation of the macrocycles. This competition can manifest via the shifting of the tautomerization equilibrium and the decreasing electron donating ability of nitrogen upon the coordination of metal ions. According to the Henderson-Hasselbalch 
A

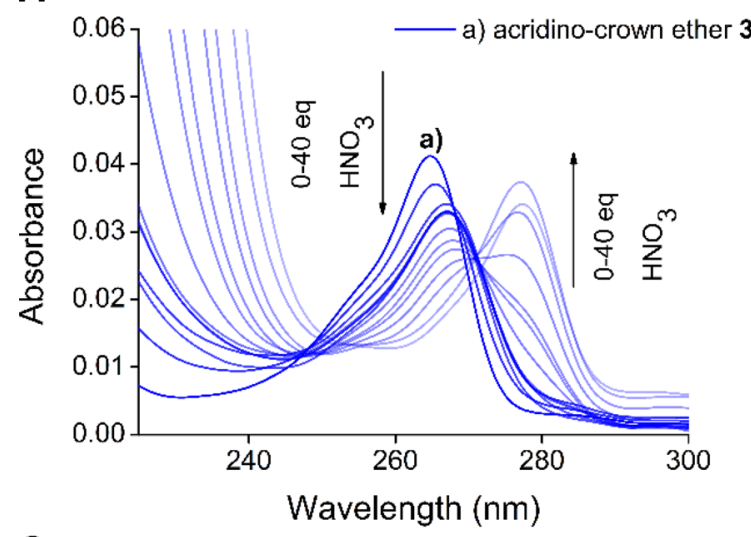

C

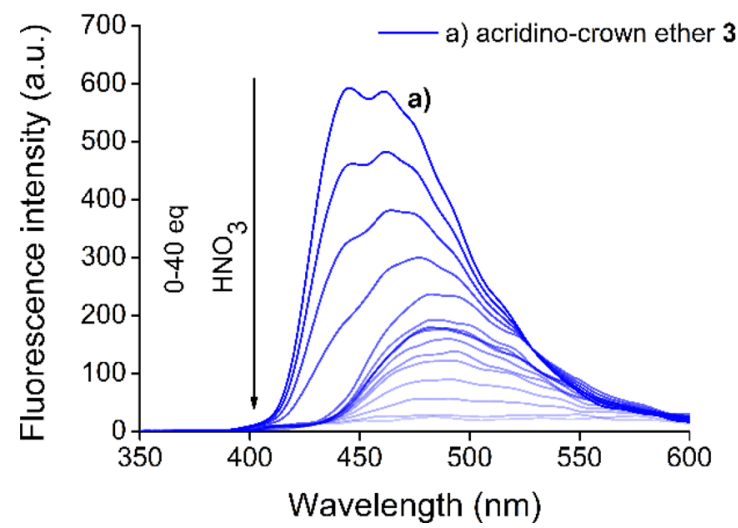

Fig. 5 Series of spectra for UV/Vis- and fluorescence titrations of acridino-crown ether $\mathbf{3}$ with nitric acid (a: Changes in absorbance in the presence of acid, $\mathbf{b}$ : Changes in absorbances at the two different characteristic absorption bands of the macrocycle, c: Changes in fluo-
B
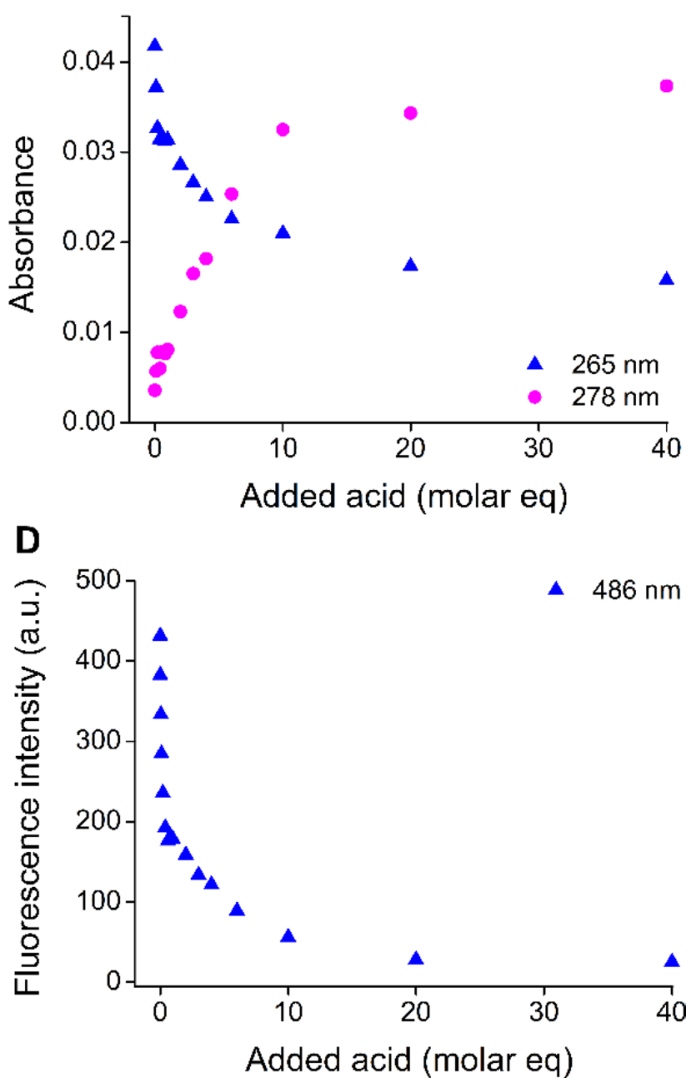

rescence intensity in the presence of acid, $\mathbf{d}$ : Changes in fluorescence intensity by adding nitric acid to macrocycle $\mathbf{3}$ at the emission maximum)

B

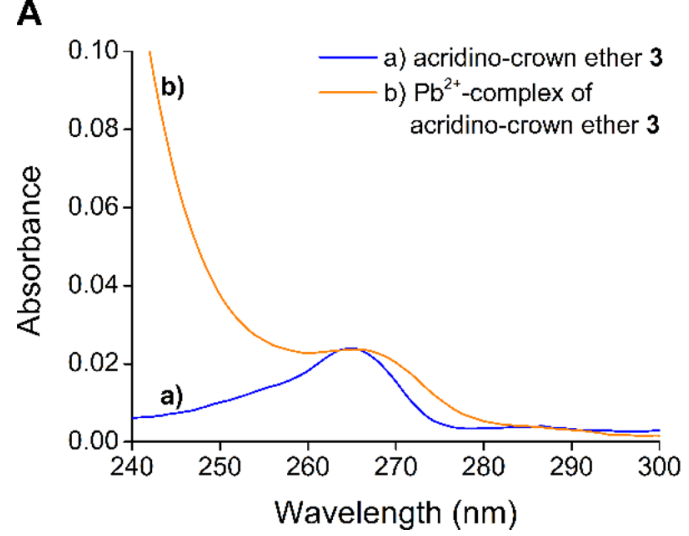

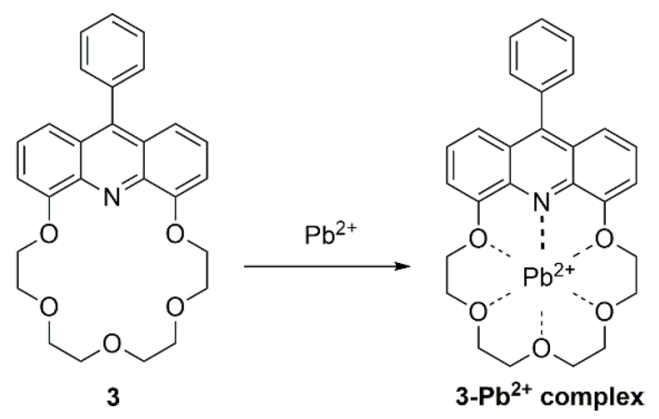

Fig. 6 Absorption spectra of free acridino-host molecule 3 and its $\mathrm{Pb}^{2+}$-complex $\left(\mathbf{a}, \mathrm{c}_{\text {crown ether }}=0.5 \mu\right.$ mol/L) and structures of the free crown ether and its $\mathrm{Pb}^{2+}$-complex (b)

equation, a significant proportion (above $10 \%$ ) of a compound with a $\mathrm{p} K_{\mathrm{a}}$ of 5.4 should already be in its protonated state at $\mathrm{pH}$ 6.3, which should cause a significant signal change of the sensors. Thus, the $\mathrm{pH}$-range for application could only be extended to about 6.3 from 7.0. Since this limit was 4.0-4.3, we can conclude that the $\mathrm{p} K_{\mathrm{a}}$ of the protonated macrocycle in the presence of $\mathrm{Pb}^{2+}$ decreased by approximately 2 units (although, due to the physical 

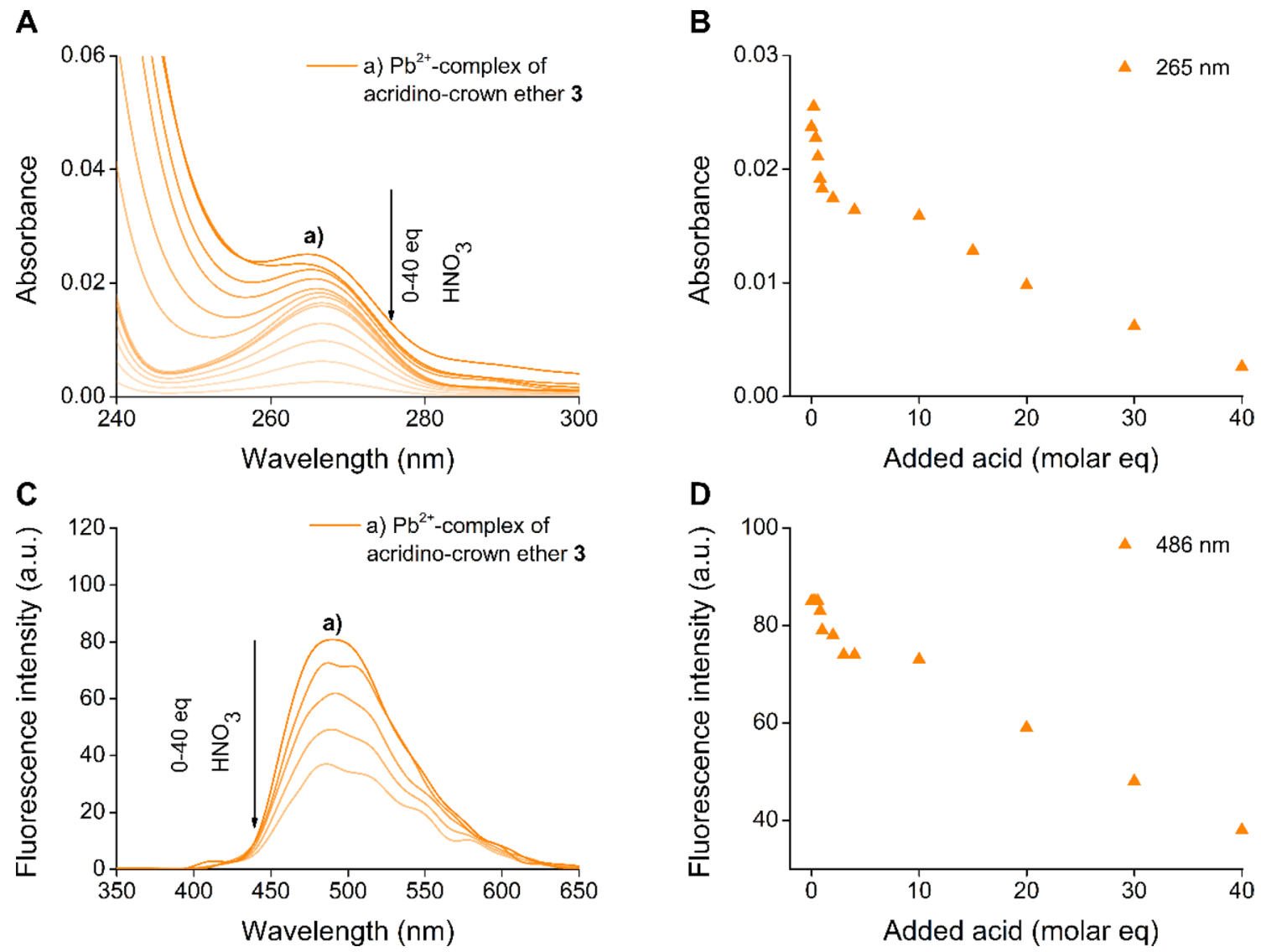

Fig. 7 Series of spectra for UV/Vis- and fluorescence titrations of the $\mathrm{Pb}^{2+}$-complex of acridino-crown ether $\mathbf{3}$ with nitric acid (a: Changes in absorbance in the presence of acid, $\mathbf{b}$ : Changes in absorbance at

the absorption maximum of the complex, $\mathbf{c}$ : Changes in fluorescence intensity in the presence of acid, $\mathbf{d}$ : Changes in fluorescence intensity by adding nitric acid to the complex at the emission maximum)
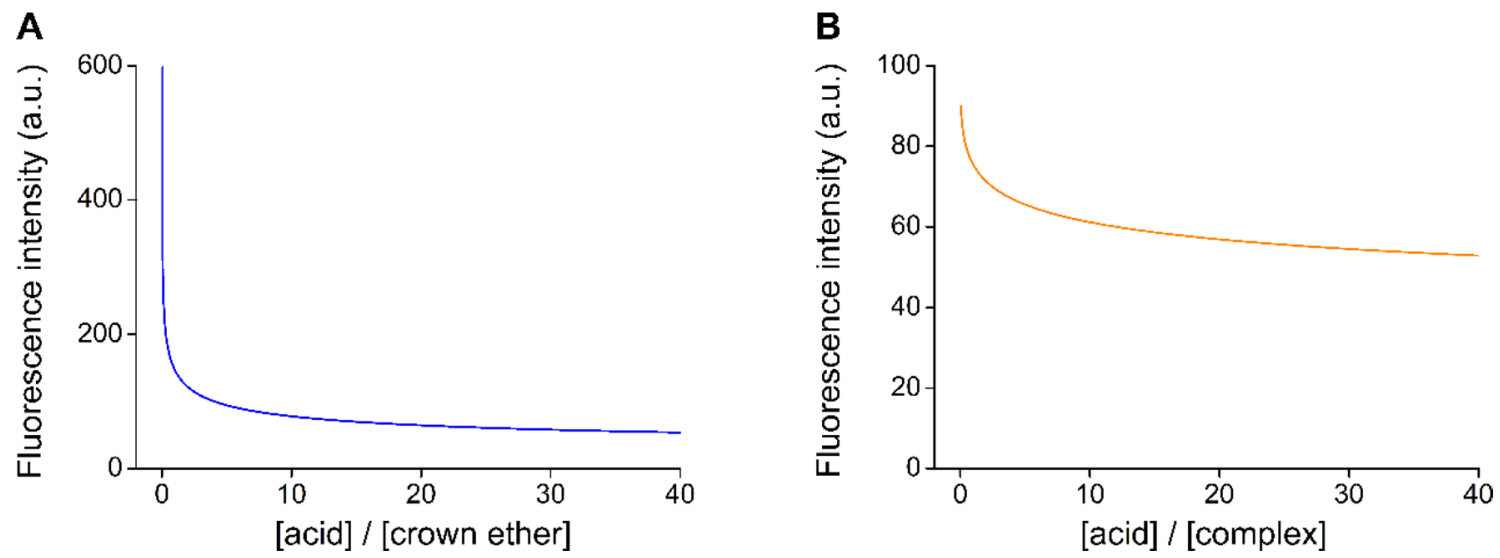

Fig. 8 Fitted nonlinear regression curves for $\mathrm{p} K_{\mathrm{a}}$ determinations of the conjugate acid of acridino-crown ether $\mathbf{3}(\mathbf{a})$ and its $\mathrm{Pb} b^{2+}$-complex $(\mathbf{b})$ based on spectroscopic titration data

immobilization of the macrocycles, tautomeric conversion may be inhibited and the equilibrium may also be effected by the altered polarity of the medium). As mentioned previously, it is not possible to determine the $\mathrm{p} K_{\mathrm{a}}$ of the protonated hydroxyacridine tautomer of acridono-crown ethers (5) based on spectrophotometry. The magnitude of the decrease in $\mathrm{p} K_{\mathrm{a}}$ values upon complexation for acridono-macrocycles can be estimated as 2 units based on the above considerations and previous studies on these types of sensor molecules [22, 23]. 


\section{Comparison of complex stability constants in neutral and acidic media}

Acridono-crown ether 4 was titrated with $\mathrm{Pb}^{2+}$, and then the $\mathrm{Pb}^{2+}$-titration was also carried out in the presence of 40 molar equivalents of acid (corresponding to the end point of the acid titration of the macrocycle). Results are shown in Fig. 9.

In both cases, nearly total fluorescence quenching was observed at the end point of the titration. In the case of neutral medium, the end point of the titration was reached by adding 10,000 molar equivalents of $\mathrm{Pb}^{2+}$, while in the case of acidic conditions more than one order of magnitude molar equivalents of $\mathrm{Pb}^{2+}$ was needed for it. Consistently, the rate of spectral change per unit of added $\mathrm{Pb}^{2+}$ also proved to be greater in neutral medium. All these prove that the host molecule forms a more stable complex in the absence of acid. In order to quantify the stability of the complexes global nonlinear regression method was similarly used to determine stability constants based on spectroscopic titration data. The fitted global nonlinear curves for $\mathrm{Pb}^{2+}$-titration data of acridono-crown ether $\mathbf{4}$ are shown in Fig. 10.

The relationships used for calculations can be found in Experimental section. The $\log K$ for the $\mathrm{Pb}^{2+}$-complex of acridono-crown ether 4 was $3.71 \pm 0.17$ in neutral medium (this $\log K$ was previously determined by Benesi-Hildebrand method based on UV/Vis titration and was found 3.64 [18]) and $\mathbf{2 . 2 2} \pm \mathbf{0 . 2 0}$ in acidic conditions (the $\log K$ determined in acidic conditions is an apparent constant). Results show that in acidic conditions, the logarithm of the complex stability constant is less by 1.49 . This can be attributed to shifting the tautomeric equilibrium toward the acridone form in acidic conditions, which tautomer of the heterocyclic unit is unfavorable for complex formation.

Stability constants were also determined for crown ether $\mathbf{3}$ containing an acridine unit in the same conditions. $\mathrm{Pb}^{2+}$-titration in neutral medium for crown ether 3 (see part a of Fig. 11) was previously carried out and the complex stability constant was determined as $\log K=5.07$ [19]. The results of $\mathrm{Pb}^{2+}$-titration of this crown ether in acidic
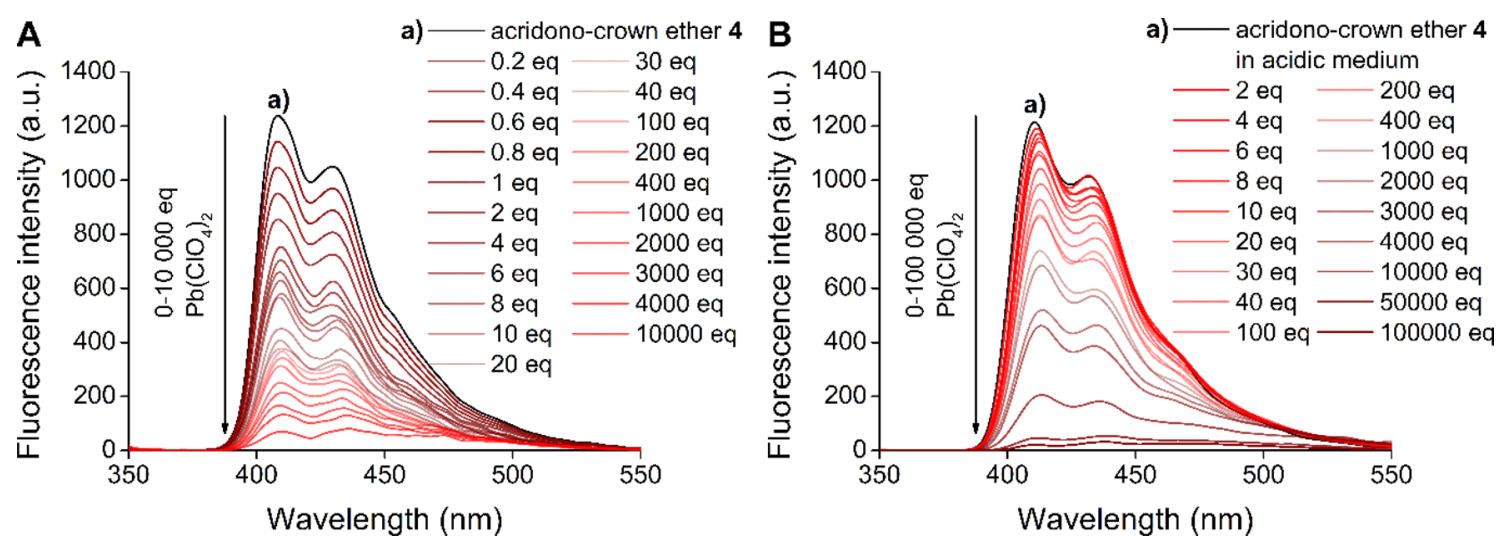

Fig. 9 Series of spectra for fluorescence titrations of acridono-macrocycle 4 with $\mathrm{Pb}^{2+}$ in neutral (a) and acidic conditions (b)
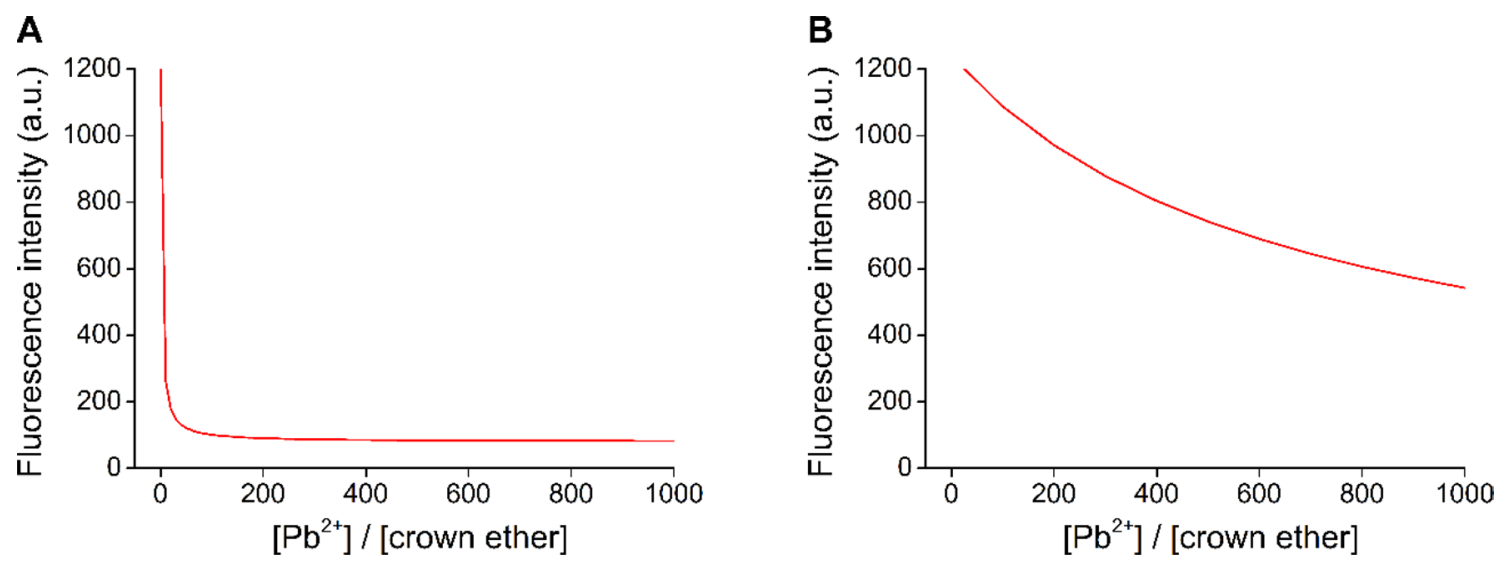

Fig. 10 Fitted nonlinear regression curves for $\log K$ determinations of the $\mathrm{Pb}^{2+}$-complex of acridono-crown ether 4 both in neutral (a) and acidic (b) conditions based on spectroscopic titration data 

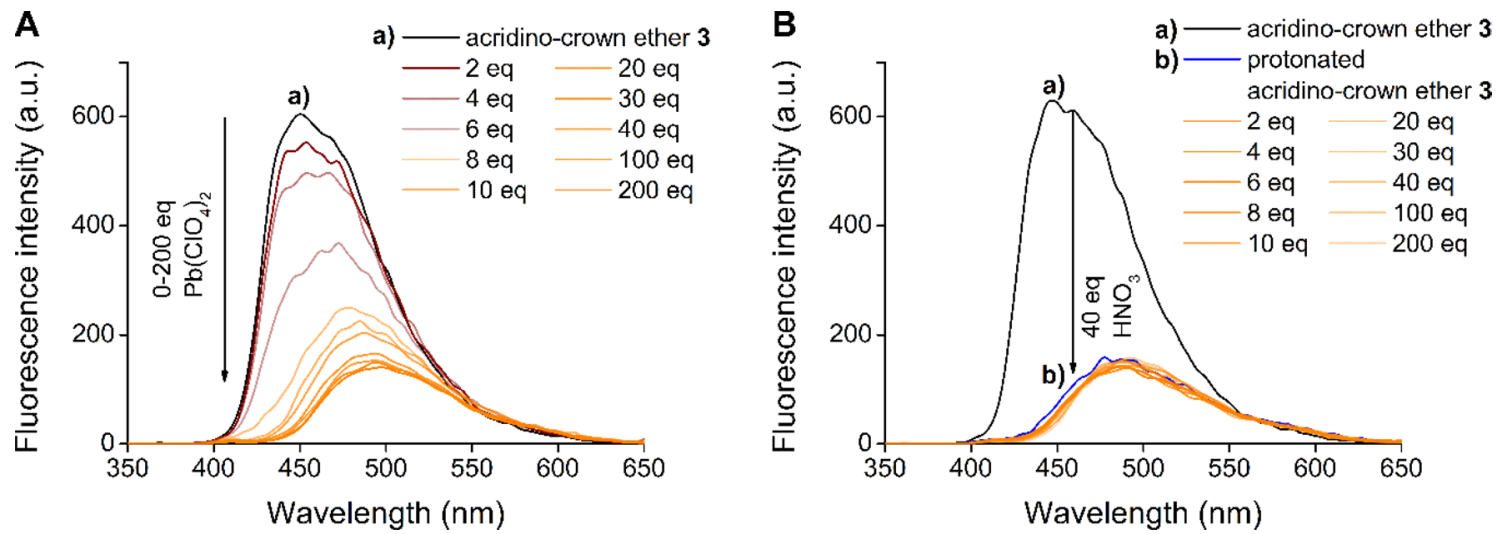

Fig. 11 Series of spectra for fluorescence $\mathrm{Pb}^{2+}$-titrations in neutral and acidic conditions for studying the complex stability toward $\mathrm{Pb}^{2+}$ in the case of the unprotonated (a) and protonated (b) acridino-macrocycle $\mathbf{3}$

conditions (after the addition of 40 molar equivalents of acid corresponding to the end point of the acid titration) are shown in part $\mathbf{B}$ of Fig. 11.

It can be seen in part b of Fig. 11 that there was no spectral change upon addition of $\mathrm{Pb}^{2+}$, thus complex formation did not take place. This is because the protonation of the acridine unit inhibits the intermolecular interactions with $\mathrm{Pb}^{2+}$.

In summary, the $\mathrm{pH}$-dependence of complexation is much less in the case of crown ethers containing the heterocyclic unit in acridone form $\left(\log K\left(\mathrm{~Pb}^{2+}\right.\right.$, neutral medium $)=3.71 \leftrightarrow \log K\left(\mathrm{~Pb}^{2+}\right.$, acidic medium $\left.)=2.22\right)$ than for macrocycles containing stabilized acridine forms $\left(\log K\left(\mathrm{~Pb}^{2+}\right.\right.$, neutral host $)=5.07 \leftrightarrow \log K\left(\mathrm{~Pb}^{2+}\right.$, protonated host $) \approx 0$ ). This can be attributed to the possibility of tautomerism. The complexation of $\mathrm{Pb}^{2+}$ is more strongly inhibited in the case of the stabilized acridine form than that of crown ethers containing an acridone unit. The inhibitory effect of protonation could be reduced by tautomerization.

Studies showed that only the acridine form of the heterocyclic unit took part in the complexation with the metal ion. If no prototropic equilibrium takes place due to the substituent at position 9 of the heterocyclic unit, a higher complex stability was obtained toward $\mathrm{Pb}^{2+}(\log K$ (acridono-crown ether 4$)=3.71 \leftrightarrow \log K$ (acridino-crown ether $3)=5.07$ ). However, in the cases of both crown ethers (host molecules $\mathbf{4}$ and $\mathbf{3}$ ) a high competition took place between protonation and complex formation. In the case of acridono-macrocycle $\mathbf{4}$, the acidic medium partially suppressed the conversion to the preferred 9-hydroxyacridine tautomer $(\mathbf{5})$, while the stabilized acridino-crown ether $(\mathbf{3})$ was unable to coordinate $\mathrm{Pb}^{2+}$ due to the protonation of its nitrogen atom. It also indicates the key role of the nitrogen atom among the other donor atoms of the macrocycle in molecular recognition.

\section{Conclusions}

Comparison of the reported types of sensor molecules was carried out using hosts $\mathbf{3}$ and $\mathbf{4}$ as model compounds, which are suitable candidates for general studies on factors influencing practical applications. In the case of acridino-crown ethers the acid inhibits complex formation more strongly ( $\Delta \log K$ ( $\log K$ change upon acidifying) for the complexes of acridino-crown ether $\approx 5 \leftrightarrow \Delta \log K$ for the complexes of acridono-crown ether $=1.49$ ), while in the case of acridonomacrocycles the complexation of the guest cation inhibits protonation more strongly $\left(\Delta \mathrm{p} K_{\mathrm{a}}\left(\mathrm{p} K_{\mathrm{a}}\right.\right.$ change upon addition of $\mathrm{Pb}^{2+}$ ) for acridono-crown ether $\approx 2 \leftrightarrow \Delta \mathrm{p} K_{\mathrm{a}}$ for acridinocrown ether $=0.9$ ) and vice versa. Therefore, in the case of the acridono-macrocycles, complexation is less sensitive to acid and the $\mathrm{pH}$-sensitivity of the crown ethers decreases even more after complexation. There is a weak competition in this case. The $\mathrm{p} K_{\mathrm{a}}$ of the protonated acridino-crown ether (3) changes only half as much upon complex formation than it does of the hydroxyacridine tautomer (5) of acridono-crown ethers (4). There is a strong competition. Complexation is more strongly inhibited in this case and the presence of the preferred guest cation can only slightly compensate the effect of the acidic medium, even that the acridino-crown ether (3) forms a complex with more than 1 order of magnitude higher stability toward $\mathrm{Pb}^{2+}$ compared to the acridono-analogue (4).

Therefore, in terms of $\mathrm{pH}$-sensitivity, crown ethers containing an acridone unit are more advantageous. From an application point of view, the $\mathrm{pH}$ of the medium is one of the most limiting conditions effecting the practical use of the macrocycles. This inhibitory effect can easily be limited in the case of the hydroxyacridine form of the studied heterocyclic units. Thus, crown ethers containing an acridone unit are recommended for the development of cation-complexationbased applications. Naturally, the macrocycles containing a 
heteroaromatic unit in a stabilized acridine form could also be advantageous, especially for selector applications in the case of organic guests. In this case a fixed and stabilized acridine form is required, which can be obtained by substitution at position 9 of the heterocycle. However, the change in the $\mathrm{pH}$ of the medium can be a strongly limiting factor for complex formation.

\section{Experimental}

Materials and solvents were purchased from Sigma-Aldrich Corporation (USA, owned by Merck) and their purity was analytical grade. Macrocyclic model compounds were prepared as reported [19, 24]. UV/Vis spectra were recorded on a UNICAM UV4-100 spectrophotometer controlled by VIZION 3.4 software (ATI UNICAM, UK). Fluorescence emission spectra were recorded on a Perkin-Elmer LS 50B luminescent spectrometer (PerkinElmer Inc., USA) and were corrected by FL Winlab 3.0 spectrometer software (PerkinElmer Inc., USA). Quartz cuvettes with path length of $1 \mathrm{~cm}$ were used in all cases. The concentrations of the solutions of macrocycles were $1.0 \mu \mathrm{mol} / \mathrm{L}$ in acetonitrile for the acid titrations and $0.5 \mu \mathrm{mol} / \mathrm{L}$ in acetonitrile for the titrations with $\mathrm{Pb}^{2+}$. For spectrophotometric titrations, the hydrogen perchlorate salts of $\mathrm{Pb}^{2+}$ in acetonitrile or concentrated nitric acid in acetonitrile were added to the solutions containing the crown ether using a Hamilton-syringe. The results were corrected with the background signal and the dilution effect of the added solutions. Every titrant solution was added until constant optical signal was observed which state was defined as the end point of the titration experiment. In the case of fluorescence measurements an excitation wavelength of 251 of associated proton / molecule, $F_{\min }$ is the fluorescence intensity at the end point of acid titration, $K_{\text {acid }}$ is the acid dissociation constant of the investigated compound. The $\mathrm{p} K_{\mathrm{a}}$ values were determined by global nonlinear regression analysis using OriginPro 8.6 (OriginLab Corp., USA) software. During the fitting method, the $n$ and the $K_{\text {acid }}$ were defined as parameters in the equation. The value of $n$ proved to be close to 1 , thus it was set as a constant. Hence, based on the known values of variable $\left[\mathrm{H}^{+}\right]$and the wavelengthdependent variables $F, F_{\max }, F_{\min }$, parameter $K_{\text {acid }}$ can be determined. During the calculation it was considered that the proton dissociation of nitric acid is strongly reduced in acetonitrile compared to the estimated total dissociation of protons in water. The $\mathrm{p} K_{\mathrm{a}}$ for nitric acid in acetonitrile is $10.6[26]$. The $\left[\mathrm{H}^{+}\right]$values in Eq. 1 were corrected with the degree of dissociation corresponding to the concentration of nitric acid using the Ostwald's dilution law.

The stability constants of the complexes were also determined by global nonlinear regression analysis using the same software. For determination of the complex stability constant based on the observed fluorescence quenching by complexation, the following equation was used [27]:

$\frac{F_{0}-F}{F_{0}-F_{c}}=\frac{[H]+[L]+\frac{1}{K_{a}}-\sqrt{\left([H]+[L]+\frac{1}{K_{a}}\right)^{2}-4 \cdot[H] \cdot[L]}}{2 \cdot[H]}$

where $F$ is the measured fluorescence intensity, $F_{0}$ is the starting fluorescence of the host molecule, $F_{c}$ is the fluorescence of the fully complexed host, $K_{\alpha}$ the association constant of the complex, $[\mathrm{H}]$ the concentration of host, $[\mathrm{L}]$ the concentration of the added ligand at a given point of titration. For easier handling, the equation has been aligned to F:

$F=F_{0}-\left(F_{0}-F_{c}\right) \cdot \frac{[H]+[L]+\frac{1}{K_{a}}-\sqrt{\left([H]+[L]+\frac{1}{K_{a}}\right)^{2}-4 \cdot[H] \cdot[L]}}{2 \cdot[H]}$

$\mathrm{nm}$ was used for the acridono- and $265 \mathrm{~nm}$ for the acridinomodel compound. The complex stability constants and the $\mathrm{p} K_{\mathrm{a}}$ were also determined in acetonitrile at $25 \pm 1{ }^{\circ} \mathrm{C}$.

Determination of $\mathrm{p} K_{\mathrm{a}}$ values in non-aqueous medium was carried out based on the following equation [25]:

$$
F=\frac{F_{\text {max }}\left[H^{+}\right]^{n}+F_{\text {min }} K_{\text {acid }}}{K_{\text {acid }}+\left[H^{+}\right]^{n}}
$$

where $F$ is the measured fluorescence intensity, $F_{\max }$ is the fluorescence intensity at the starting point of acid titration, $\left[\mathrm{H}^{+}\right]$refers to the proton concentration, $n$ shows the number
$F_{0}$ is a wavelength-dependent variable and [L] was set as a variable, too. During fitting, $\mathrm{F}_{\mathrm{c}}$ and $K_{\alpha}$ were defined as parameters, while the values of $[\mathrm{H}]$ were given as constants.

Acknowledgements The authors express their thanks to Dániel Ster for his valuable technical assistance during this work. The financial support of the National Research, Development and Innovation Office (Grant Number: K128473) is gratefully acknowledged.

Author Contributions ÁG: Conceptualization, Methodology, Formal analysis, Writing - Original Draft; PV: Investigation, Visualization, Writing - Review \& Editing; BAA: Visualization, Writing - Original Draft; PH: Writing - Review \& Editing, Supervision, Funding 
acquisition; TT: Writing - Review \& Editing, Supervision, Project administration.

Funding Open access funding provided by Budapest University of Technology and Economics.

\section{Declarations}

Conflict of interest The authors declare no conflicts of interest. The funding institution had no role in the design of the study; in the collection, analyses, or interpretation of data; in the writing of the manuscript, and in the decision to publish the results.

Open Access This article is licensed under a Creative Commons Attribution 4.0 International License, which permits use, sharing, adaptation, distribution and reproduction in any medium or format, as long as you give appropriate credit to the original author(s) and the source, provide a link to the Creative Commons licence, and indicate if changes were made. The images or other third party material in this article are included in the article's Creative Commons licence, unless indicated otherwise in a credit line to the material. If material is not included in the article's Creative Commons licence and your intended use is not permitted by statutory regulation or exceeds the permitted use, you will need to obtain permission directly from the copyright holder. To view a copy of this licence, visit http://creativecommons.org/licenses/by/4.0/.

\section{References}

1. Ježek, J., Hlaváček, J., Šebestík, J. (2017) Progress in Drug Research: Biomedical Applications of Acridines, 1st ed., Springer International Publishing, A.G., Cham, Switzerland, 72, pp. 47-207. eBook ISBN: 978-3-319-63953-6, https://doi. org/10.1007/978-3-319-63953-6

2. Huszthy, P., Samu, E., Vermes, B., Mezey-Vándor, G., Nógrádi, M., Bradshaw, J.S., Izatt, R.M.: Synthesis of novel acridino-and phenazino-18-crown-6 ligands and their optically pure dimethyl-substituted analogues for molecular recognition studies. Tetrahedron. 55(5), 1491-1504 (1999). https://doi.org/10.1016/ S0040-4020(98)01128-4

3. Prodi, L., Bolletta, F., Montalti, M., Zaccheroni, N., Huszthy, P., Samu, E., Vermes, B.: Luminescence signalled enantiomeric recognition of chiral organic ammonium ions by an enantiomerically pure dimethylacridino-18-crown-6 ligand. New J. Chem. 24(10), 781-785 (2000). https://doi.org/10.1039/B004600K

4. Gawley, R.E., Shanmugasundaram, M., Thorne, J.B., Tarkka, R.M.: Selective detection of saxitoxin over tetrodotoxin using acridinylmethyl crown ether chemosensor. Toxicon. 45(6), 783-787 (2005). https://doi.org/10.1016/j.toxicon.2005.01.019

5. Orda-Zgadzaj, M., Abraham, W. (2007) Photoswitchable macrocycles incorporating acridane moieties. Synthesis (21): 33453356. https://doi.org/10.1055/s-2007-990829

6. García-Garrido, S.E., Caltagirone, C., Light, M.E., Gale, P.A.: Acridinone-based anion receptors and sensors. Chem. Commun. 14, 1450-1452 (2007). https://doi.org/10.1039/B618072H

7. Kertész, J., Huszthy, P., Kormos, A., Bertha, F., Horváth, V., Horvai, G.: Synthesis of new optically active acridino18-crown-6 ligands and studies of their potentiometric selectivity toward the enantiomers of protonated 1-phenylethylamine and metal ions. Tetrahedron: Asymmetry. 20(24), 2795-2801 (2009). https://doi.org/10.1016/j.tetasy.2009.11.011

8. Móczár, I., Huszthy, P., Mezei, A., Kádár, M., Nyitrai, J., Tóth, K.: Synthesis and optical characterization of novel azacrown ethers containing an acridinone or an $N$-methylacridinone unit as potential fluorescent chemosensors. Tetrahedron. 66(1), 350-358 (2010).https://doi.org/10.1016/j.tet.2009.10.076

9. Kertész, J., Bognár, B., Kormos, A., Móczár, I., Baranyai, P., Kubinyi, M., Kálai, T., Hideg, K., Huszthy, P.: Synthesis and metal ion complexation of spin labeled 18-crown-6 ethers containing an acridone or an acridine fluorophore unit. Tetrahedron. 67(46), 8860-8864 (2011). https://doi.org/10.1016/j.tet.2011. 09.092

10. Rapi, Z., Bakó, P., Keglevich, G., Baranyai, P., Kubinyi, M., Varga, O.: Synthesis and recognition properties of $\alpha$-D-glucosebased fluorescent crown ethers incorporating an acridine unit. J. Incl. Phenom. Macrocycl. Chem. 80(3-4), 253-261 (2014). https://doi.org/10.1007/s10847-014-0384-8

11. Yousuf, M., Ahmed, N., Shirinfar, B., Miriyala, V.M., Youn, I.S., Kim, K.S.: Precise tuning of cationic cyclophanes toward highly selective fluorogenic recognition of specific biophosphate anions. Org. Lett. 16(8), 2150-2153 (2014). https://doi. org/10.1021/ol500613y

12. Bartoli, F., Bencini, A., Garau, A., Giorgi, C., Lippolis, V., Lunghi, A., Totti, F., Valtancoli, B.: Di- and triphosphate recognition and sensing with mono- and dinuclear fluorescent zinc(II) complexes: Clues for the design of selective chemosensors for anions in aqueous media. Chem-A Eu J. 22(42), 14890-14901 (2016). https://doi.org/10.1002/chem.201602079

13. Zhou, J., Yuan, Y.F., Zhuo, J.B., Lin, C.X.: Synthesis and characterization of cyclophane: The highly selective recognition of $\mathrm{Fe}^{3+}$ in aqueous solution and $\mathrm{H}_{2} \mathrm{PO}_{4}^{-}$in acetonitrile solution. Tetrahedron Lett. 59(11), 1059-1064 (2018).https://doi.org/10. 1016/j.tetlet.2018.02.005

14. Wang, C., Fu, J., Yao, K., Xue, K., Xu, K., Pang, X.: Acridinebased fluorescence chemosensors for selective sensing of $\mathrm{Fe}^{3+}$ and $\mathrm{Ni}^{2+}$ ions. Spectrochim. Acta Part A Mol. Biomol. Spectrosc. 199, 403-411 (2018). https://doi.org/10.1016/j.saa.2018. 03.015

15. Khurana, R., Barooah, N., Bhasikuttan, A.C., Mohanty, J.: Modulation in the acidity constant of acridine dye with cucurbiturils: stimuli-responsive $\mathrm{p} K_{\mathrm{a}}$ tuning and dye relocation into live cells. Org. Biomol. Chem. 15(39), 8448-8457 (2017). https://doi.org/ 10.1039/C7OB02135F

16. Szalay, L., Farkas, V., Vass, E., Hollósi, M., Móczár, I., Pintér, Á, Huszthy, P.: Synthesis and selective lead(II) binding of achiral and enantiomerically pure chiral acridono-18-crown-6 ether type ligands. Tetrahedron: Asymmetry. 15(9), 1487-1493 (2004). https://doi.org/10.1016/j.tetasy.2004.03.024

17. Németh, T., Golcs, Á, Leveles, I., Tóth, T., Vértessy, B.G., Huszthy, P.: Structural characterization of a complex derived from lead(II) perchlorate and acridono-18-crown-6 ether. Struct. Chem. 26(5-6), 1467-1471 (2015). https://doi.org/10.1007/ s11224-015-0657-x

18. Németh, T., Kormos, A., Tóth, T., Balogh, G.T., Huszthy, P.: Synthesis and cation binding of acridono-18-crown-6 ether type ligands. Monatshefte für Chemie-Chemical Monthly. 146(8), 1291-1297 (2015). https://doi.org/10.1007/s00706-015-1454-3

19. Németh, T., Tóth, T., Balogh, G.T., Huszthy, P.: Synthesis and fluorescence spectroscopic studies of novel 9-phenylacridino18-crown-6 ether type sensor molecules. Periodica Polytechnica Chemical Engineering. 61(4), 249-257 (2017). https://doi.org/ 10.3311/PPch.11277

20. Kádár, M., Biró, A., Tóth, K., Vermes, B., Huszthy, P.: Spectrophotometric determination of the dissociation constants of crown ethers with grafted acridone unit in methanol based on Benesi-Hildebrand evaluation. Spectrochim. Acta Part A Mol. Biomol. Spectrosc. 62(4-5), 1032-1038 (2005). https://doi.org/ 10.1016/j.saa.2005.04.034 
21. Samsonova, L.G., Selivanov, N.I., Kopylova, T.N., Artyukhov, V.Y., Maier, G.V., Plotnikov, V.G., Sazhnikov, V.A., Khlebunov, A.A., Alfimov, M.V.: Experimental and theoretical investigation of the spectral and luminescent properties of some acridine compounds. High Energy Chem. 43(2), 105-115 (2009). https://doi.org/10.1134/S0018143909020076

22. Golcs, Á, Horváth, V., Huszthy, P., Tóth, T.: Fast potentiometric analysis of lead in aqueous medium under competitive conditions using an acridono-crown ether neutral ionophore. Sensors. 18(5), 1407-1420 (2018). https://doi.org/10.3390/s18051407

23. Golcs, Á, Ádám, B., Horváth, V., Tóth, T., Huszthy, P.: Synthesis, molecular recognition study and liquid membrane-based applications of highly lipophilic enantiopure acridino-crown ethers. Molecules. 25(11), 2571-2593 (2020). https://doi.org/ 10.3390/molecules25112571

24. Huszthy, P., Köntös, Z., Vermes, B., Pintér, Á: Synthesis of novel fluorescent acridono- and thioacridono-18-crown-6 ligands. Tetrahedron. 57(23), 4967-4975 (2001). https://doi. org/10.1016/S0040-4020(01)00408-2
25. Baruah, M., Qin, W., Flors, C., Hofkens, J., Vallee, R.A., Beljonne, D., Van der Auweraer, M., De Borggraeve, W.M., Boens, N.: Solvent and $\mathrm{pH}$ dependent fluorescent properties of a dimethylaminostyryl borondipyrromethene dye in solution. The Journal of Physical Chemistry A. 110(18), 5998-6009 (2006). https://doi.org/10.1021/jp054878u

26. Kolthoff, I.M., Chantooni, M.K.: Dissociation constant, $K_{\mathrm{a}}$, and stability constant, $K\left(\mathrm{HA}_{2}{ }^{-}\right)$, of the $1: 1$ homoconjugate of sulfuric and nitric acids in acetonitrile at $298.1 \mathrm{~K}$. Revised values. Journal of Chemical \& Engineering Data. 44(1), 124-129 (1999). https://doi.org/10.1021/je9801922

27. Van de Weert, M., Stella, L.: Fluorescence quenching and ligand binding: A critical discussion of a popular methodology. J. Mol. Struct. 998(1-3), 144-150 (2011). https://doi.org/10.1016/j.molst ruc.2011.05.023

Publisher's Note Springer Nature remains neutral with regard to jurisdictional claims in published maps and institutional affiliations. 